\title{
New Assessment of the Completeness of Vagotomy and the Selection of Operation for Duodenal Ulcer Based upon Gastric Pepsin Secretion
}

\author{
Jin-Ichi Kameyama, Takeshi Sekine and Toshio Sato \\ Department of Surgery, Tohoku University School of Medicine, \\ Sendai 980
}

\begin{abstract}
KaneydMa, J., Sekine, T. and Sato, T. New Assessment of the Completeness of Vagotomy and the Selection of Operation for Duodenal Ulcer Based upon Gastric Pepsin Secretion. Tohoku J. exp. Med., 1980, 130 (2), 183-188 — On the basis of the study of gastric pepsin secretion before and after operation for duodenal ulcer, the assessment of the completeness of vagotomy and the selection of operation were attempted. Vagotomy with pyloroplasty that results in a postoperative peak pepsin output (PPO) after insulin stimulation of less than $100 \mathrm{mg}$ tyrosine/hr may well be considered as representing complete vagotomy. In view of the evaluation of ulcer recurrence, this criterion was confirmed to be a more reliable index compared with the criteria based upon gastric acid secretion. Therefore, concerning the selection of operation for duodenal ulcer on the basis of gastric pepsin secretion, we propose the following criteria: Vagotomy with pyloroplasty should be indicated for patients with an insulin-stimulated preoperative PPO less than $500 \mathrm{mg}$ tyrosine $/ \mathrm{hr}$; vagotomy with hemigastrectomy for those with $500-1250 \mathrm{mg}$ tyrosine $/ \mathrm{hr}$; and distal gastrectomy such as Billroth I operation for those with over $1250 \mathrm{mg}$ tyrosine/hr. - — gastric pepsin secretion; duodenal ulcer; recurrent ulcer; assessment of the completeness of vagotomy; selection of operation
\end{abstract}

In order to preserve the physiological function of the stomach as much as possible, various types of operation for duodenal ulcer have been devised. Although many reports dealt with gastric acid secretion in duodenal ulcer, a few reports are available for gastric pepsin secretion. The present study was thus undertaken to investigate gastric pepsin secretion before and after operation for duodenal ulcer. Based on the results of gastric pepsin secretion, the assessment of the completeness of vagotomy, and then the selection of operation were studied.

\section{Patients and Methods}

The subjects comprised 71 patients with duodenal ulcer ( 62 male and 9 female, with a mean age of 38 years) from 1974 to 1978 in our Department. Vagotomy with pyloroplasty $(\mathrm{V}+\mathrm{P})$ was performed on 42 patients and vagotomy with hemigastrectomy $(\mathrm{V}+\mathrm{H})$ on 17 patients, but the remaining 12 patients were not operated on. Postoperative studies were made 4 weeks after operation. No recurrence of ulcer was noted on $\mathrm{x}$-ray or endoscopic examination in any case. Moreover, 3 cases of ulcer recurrence after vagotomy with

Received for publication, January 9, 1979. 
pyloroplasty were scrutinized according to the criteria on the basis of gastric pepsin secretion as well as gastric acid secretion.

Gastric analysis was made using regular insulin $(0.2 \mathrm{U} / \mathrm{kg}$, intravenously) as gastric secretory stimulant. Pepsin concentration was determined by the human gastric pepsin assay proposed by the Japanese Society of Gastroenterology (Committee of the Japanese Society of Gastroenterology 1974). The peak pepsin output (PPO) was obtained from two consecutive 15-min samples of the highest value after stimulation and expressed as mg tyrosine/hr.

The lowest level of blood sugar after insulin stimulation was less than $50 \mathrm{mg} / 100 \mathrm{ml}$ in all cases, favorably corresponding to the insulin test (Hollander 1948).

In statistical analysis, the measured values were expressed as mean \pm s.E. The regular distribution of preoperative PPO was determined by using Shapiro-Francia's method.

\section{Results}

\section{Insulin-stimulated gastric pepsin secretion before and after operation}

Gastric pepsin secretion began to increase within 15-30 min after insulin injection, i.e. 15-30 min earlier than the acid secretory response, and continued to be increased even after $120 \mathrm{~min}$. The mean value of preoperative PPO in all duodenal ulcer cases was $387.9 \mathrm{mg}$ tyrosine $/ \mathrm{hr}$. The mean value of preoperative $\mathrm{PPO}$ in the cases of $\mathrm{V}+\mathrm{H}(422.2 \mathrm{mg}$ tyrosine/hr) was higher than in the cases of $\mathrm{V}+\mathrm{P}$ (374.8 $\mathrm{mg}$ tyrosine/hr). On the other hand, the mean value of postoperative PPO in the cases of $\mathrm{V}+\mathrm{H}(32.5 \mathrm{mg}$ tyrosine/hr) was lower than in the cases of $\mathrm{V}+\mathrm{P}(80.6 \mathrm{mg}$ tyrosine $/ \mathrm{hr})$. The average reduction rate in $\mathrm{V}+\mathrm{H}(92 \%)$ was higher than that in $\mathrm{V}+\mathrm{P}(80 \%)$ (Table 1, Fig. 1).

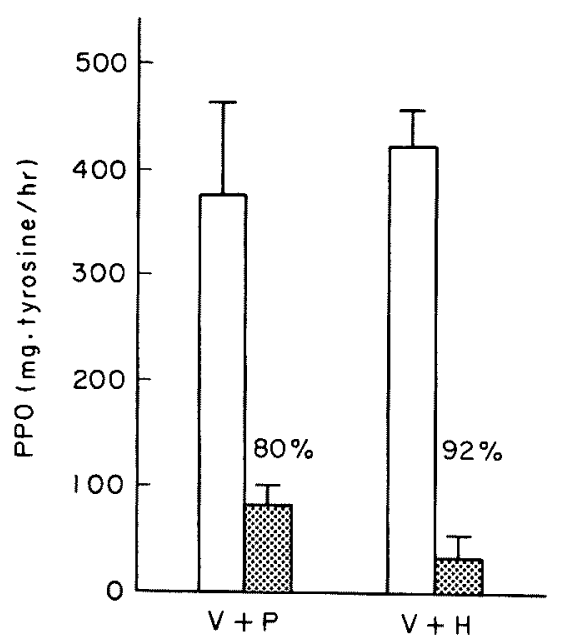

Fig. 1. Pepsin secretion (PPO) before and after operation. $\square$, before operation; , after operation; \%, average reduction rate.

\section{Distribution of preoperative PPO}

Preoperative PPOs after insulin stimulation were evaluated whether they showed the regular distribution or not. Skewness and kurtosis of the measured values were 
TABLE 1. Pepsin secretion (PPO) before and after operation

\begin{tabular}{|c|c|c|c|}
\hline \multirow{2}{*}{$\begin{array}{l}\text { Type of } \\
\text { operation }\end{array}$} & \multicolumn{2}{|c|}{ PPO (mg t tyrosine/hr) } & \multirow{2}{*}{$\begin{array}{c}\text { Average } \\
\text { reduction rate }(\%)\end{array}$} \\
\hline & Before & After & \\
\hline $\begin{array}{l}\mathrm{V}+\mathrm{P} \\
\mathrm{V}+\mathrm{H}\end{array}$ & $374.8 \pm 87.4$ & $80.6 \pm 15.8$ & 80 \\
\hline $\mathrm{V}+\mathrm{H}$ & $422.2 \pm 33.6$ & $32.5 \pm 23.7$ & 92 \\
\hline
\end{tabular}

1.57 and 6.17 , respectively, and the measured values did not show a good regular distribution. However, skewness and kurtosis of the values after natural logarithmic transformation were 0.25 and 2.93 , respectively. These transformed values showed more favorably a regular distribution than the measured values. After natural logarithmic transformation, the mean value of preoperative PPO $(m)$ and its standard deviation $(\sigma)$ were 5.88 and 0.41 , respectively.

Assessment of the completeness of vagotomy based upon gastric acid secretion and gastric pepsin secretion.

The insulin test after $\mathrm{V}+\mathrm{P}$ was performed in 42 cases without recurrent ulcer and 3 cases with recurrent ulcer. The criterion of Ross and Kay (1964) for the completeness of vagotomy, which is based upon the measurement of gastric acid secretion, is widely accepted as the most reliable means. Of 42 cases without recurrent ulcer, 7 showed early positive response. However, no recurrence of ulcer was noted in these 7 cases on $x$-ray or endoscopic examination. On the other hand, 3 cases with recurrent ulcer did not show early positive response (Fig. 2). Therefore, there was no relationship between the criterion of Ross and Kay and

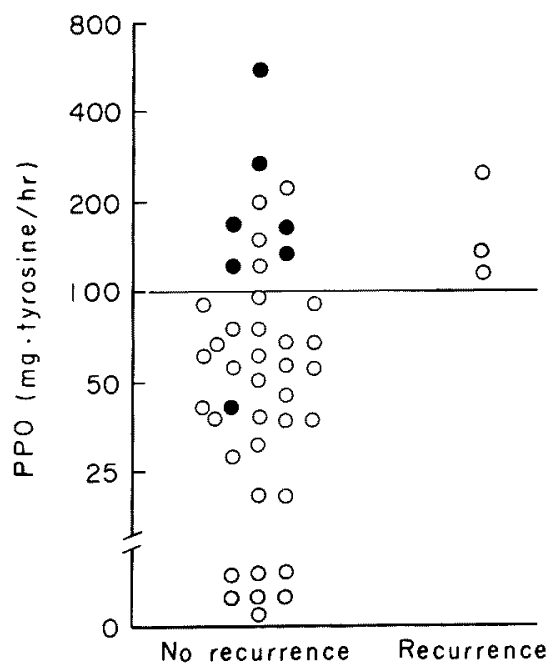

Fig. 2. Postoperative pepsin secretion (PPO) with and without recurrent ulcer. Criterion of Ross and Kay. e, early positive response; 0 , late positive or negative response. 
the recurrence of ulcer. Of 42 cases without recurrent ulcer performed $\mathrm{V}+\mathrm{P}, 32$ had PPO less than $100 \mathrm{mg}$ tyrosine/hr. The remaining $10(24 \%)$ had a postoperative PPO more than $100 \mathrm{mg}$ tyrosine/hr. However, all of the 3 recurrent ulcers had a postoperative PPO more than $100 \mathrm{mg}$ tyrosine/hr (Fig. 2).

\section{Discussion}

In order to preserve the physiological function of the stomach as much as possible, various types of operation, especially vagotomy, have been devised for duodenal ulcer. However, it has been pointed out that recurrent ulcer occurred after incomplete vagotomy. From the point of view of ulcer recurrence, it would be an important problem whether vagotomy was performed completely or not. In reference to criteria for the completeness of vagotomy, Hollander (1948) first advocated the criterion based upon the measurement of gastric acid secretion. Clinically, this criterion was not related with ulcer recurrence. Thereafter Ross and Kay (1964) proposed a modified criterion, and it is widely accepted as the most adequate and reliable one for the completeness of vagotomy. In the present study, we examined 3 cases of recurrent ulcer after vagotomy and pyloroplasty according to the criterion of Ross and Kay (1964). None of these cases showed an early positive response. Further, of 42 cases, 7 showed an early positive response, revealing no recurrence of ulcer on $\mathrm{x}$-ray or endoscopic examination. There was no relationship between the criterion of Ross and Kay (1964) and the recurrence of ulcer. Therefore, it seemed that the criterion of Ross and Kay based upon gastric acid secretion would not be available for the purpose of the assessment of the completeness of vagotomy.

Gastric acid and pepsin are the most important aggressive factors in ulcer formation (Alphin et al. 1977; Nagamachi and Skoryna 1977). However, Hirschowitz and Sachs (1965), Rosato et al. (1971), Roland et al. (1974) and Kameyama and Sekine (1978) reported that the pepsin secretion was more intimately related with vagal innervation than the acid secretion. Limbosch et al. (1971) and Kameyama et al. (1978) reported that the pepsin secretion after insulin stimulation provided a more reliable index to the completeness of vagotomy than did the acid secretion. Therefore, the assessment of the completeness of vagotomy based upon gastric pepsin secretion was examined. As mentioned above, all of recurrent ulcers had a postoperative PPO more than $100 \mathrm{mg}$ tyrosine/hr, but no recurrence of ulcer was found in patients with less than this value. Recently, Faber et al. (1974), using insulin-stimulated PAO for assessing the completeness of vagotomy, performed natural logarithmic transformation of the measured values and stated that the transformed values were more favorable for the statistical analysis since they showed an accurately regular distribution. According to Faber's idea, we examined the distribution about the measured values of preoperative PPO after insulin stimulation and found that they did not show a good regular distribution. However, after natural logarithmic transformation, the transformed values of preoperative PPO showed more an accurately regular distribution than the measured 
values. Therefore, we performed the statistical analysis in terms of natural logarithmic transformation. As for no recurrence of ulcer, first we considered the range of preoperative PPO to be the $99 \%$ tolerance limit. Secondly, we considered that a postoperative PPO must be lower than the lowest range of preoperative PPO. Thus, the lowest range of preoperative PPO after natural logarithmic transformation $(m-3 \sigma)$ was 4.65 . This value corresponded to the measured value of $104.9 \mathrm{mg}$ tyrosine/hr. For convenience sake, we counted this value as $100 \mathrm{mg}$ tyrosine/hr. From the point of view of clinical observation and statistical analysis, vagotomy with pyloroplasty that results in a postoperative PPO after insulin stimulation of less than $100 \mathrm{mg}$ tyrosine/hr may well be considered as representing complete vagotomy.

The selection of operation for duodenal ulcer based upon gastric pepsin secretion was examined. As mentioned above, a preferable postoperative PPO must be under $100 \mathrm{mg}$ tyrosine $/ \mathrm{hr}$. Since the average reduction rate of PPO was $80 \%$ after $\mathrm{V}+\mathrm{P}$ and $92 \%$ after $\mathrm{V}+\mathrm{H}$, such a preferable postoperative $\mathrm{PPO}$ would be attained by $\mathrm{V}+\mathrm{P}$ in patients who have a preoperative PPO less than $500 \mathrm{mg}$ tyrosine/ $\mathrm{hr}$, and by $\mathrm{V}+\mathrm{H}$ in those who have a preoperative PPO less than $1250 \mathrm{mg}$ tyrosine/ $\mathrm{hr}$. In view of the preservation of the physiological function of the stomach as much as possible, we propose the following criteria: $\mathrm{V}+\mathrm{P}$ should be indicated for patients with an insulin-stimulated preoperative PPO less than $500 \mathrm{mg}$ tyrosine/ $\mathrm{hr}$, and $\mathrm{V}+\mathrm{H}$ for those with $500-1250 \mathrm{mg}$ tyrosine/hr. For those with a PPO over $1250 \mathrm{mg}$ tyrosine/hr, distal gastrectomy such as Billroth I operation, after which the average reduction rate of $\mathrm{PPO}$ is more higher than after $\mathrm{V}+\mathrm{P}$ and $\mathrm{V}+\mathrm{H}$ (Kameyama and Sekine 1978), should be indicated, though none of our patients had a preoperative PPO more than $1000 \mathrm{mg}$ tyrosine/hr.

\section{References}

1) Alphin, R.S., Vokac, V.A., Gregory, R.L., Bolton, P.M. \& Tawes, J.W. (1977) Role of intragastric pressure, $\mathrm{pH}$, and pepsin in gastric ulceration in the rat. Gastroenterology, 73, 495-500.

2) Committee of the Japanese Society of Gastroenterology (1974) Human gastric pepsin assay. Jap. J. Gastroent., 71, 207. (Japanese)

3) Faber, R.G., Russell, R.C.G., Parkin, J.V., Whitfield, P. \& Hobsley, M. (1974) The predictive accuracy of the postvagotomy insulin test: A new interpretation. Gut, 16, $337-342$.

4) Hirschowitz, B.1. \& Sachs, G. (1965) Vagal gastric secretory stimulation by 2-deoxyD-glucose. Amer. J. Physiol., 209, 452-460.

5) Hollander, F. (1948) Laboratory procedures in the study of vagotomy with particular reference to the insulin test. Gastroenterology, 11, 419-425.

6) Kameyama, J. \& Sekine, T. (1978) Studies on pepsin and acid secretion following various operations for gastric and duodenal ulcer. Jap. J. Gastroent., 75, 9-19. (Japanese)

7) Kameyama, J., Sekine, T., Sasaki, I., Momono, S., Yamazaki, T., Sato, T., Lin, J., Kaneko, Y., Mochizuki, F. \& Tsukui, H. (1978) Assessment of the completeness of vagotomy for duodenal uleer based upon gastric pepsin secretion. Geka, 40, 775-778. (Japanese)

8) Limbosch, J.M., Woussen-Colle, M.C. \& De Graef, J. (1971) Acid and pepsin secretion in response to insulin after truncal vagotomy in man. Digestion, 4, 281-288. 
9) Nagamachi, Y. \& Skoryna, S.C. (1977) Pepsin and acid secretion during and after gastric operations in patients with duodenal ulcer. Canad. J. Surg., 20, 239-243.

10) Roland, M., Berstad, A. \& Liavåg, I. (1974) Acid and pepsin secretion in duodenal ulcer patients in response to graded doses of pentagastrin or pentagastrin and carbacholine before and after proximal gastric vagotomy. Scand. J. Gastroent., 9, 511-518.

11) Rosato, E.F., Rosato, F.E. \& MacFadyen, B. (1971) Effect of truncal vagotomy on acid and pepsin responses to histamine in duodenal ulcer subjects. Ann. Surg., 173, $63-66$.

12) Ross, B. \& Kay, A.W. (1964) The insulin test after vagotomy. Gastroenterology, 46, 379-385. 